\title{
BMI open The incidence of eating disorders in the UK in 2000-2009: findings from the General Practice Research Database
}

\author{
Nadia Micali, ${ }^{1}$ Katrina W Hagberg, ${ }^{2}$ Irene Petersen, ${ }^{3}$ Janet L Treasure ${ }^{4}$
}

To cite: Micali N,

Hagberg KW, Petersen I, et al. The incidence of eating disorders in the UK in 20002009: findings from the General Practice Research Database. BMJ Open 2013;3: e002646. doi:10.1136/ bmjopen-2013-002646

- Prepublication history and additional material for this paper are available online. To view these files please visit the journal online (http://dx.doi.org/10.1136/ bmjopen-2013-002646).

Received 28 January 2013 Revised 18 March 2013 Accepted 3 April 2013

This final article is available for use under the terms of the Creative Commons Attribution Non-Commercial 2.0 Licence; see http://bmjopen.bmj.com

\footnotetext{
${ }^{1}$ Behavioural and Brain Sciences Unit, Institute of Child Health, University College London, London, UK ${ }^{2}$ Boston Collaborative Drug Surveillance Program, Boston University School of Public Health, Lexington, Massachusetts, USA

${ }^{3}$ Department of Primary Care and Population Health, University College London Medical School, London, UK ${ }^{4}$ Eating Disorders Research Unit, Department of Psychological Medicine, King's College London, Institute of Psychiatry, London, UK
}

Correspondence to Dr Nadia Micali; n.micali@ucl.ac.uk

\section{ABSTRACT}

Objectives: Few studies have investigated the incidence of eating disorders (EDs). Important questions about changes in the incidence of diagnosed disorders in recent years, disorder and gender-specific onset and case detection remain unanswered. Understanding changes in incidence is important for public health, clinical practice and service provision. The aim of this study was to estimate the annual (agespecific, gender-specific and subtype-specific) incidence of diagnosed ED: anorexia nervosa (AN), bulimia nervosa (BN) and eating disorder not otherwise specified (EDNOS) in primary care over a 10-year period in the UK (2000-2009); to examine the changes within the study period; and to describe peak age at diagnosis. Design: Register-based study.

Setting: Primary care. Data were obtained from a primary care register, the General Practice Research Database, which contains anonymised records representing about $5 \%$ of the UK population.

Participants: All patients with a first-time diagnosis of AN, BN and EDNOS were identified.

Primary outcome: Annual crude and age-standardised incidence rates were calculated.

Results: A total of 9072 patients with a first-time diagnosis of an ED were identified. The age-standardised annual incidence rate of all diagnosed ED for ages $10-49$ increased from $32.3(95 \% \mathrm{Cl} 31.7$ to $32.9)$ to $37.2(95 \% \mathrm{Cl} 36.6$ to 37.9$)$ per 100000 between 2000 and 2009. The incidence of AN and BN was stable; however, the incidence of EDNOS increased The incidence of the diagnosed ED was highest for girls aged $15-19$ and for boys aged 10-14.

Conclusions: The age-standardised incidence of ED increased in primary care between 2000 and 2009. New diagnoses of EDNOS increased, and EDNOS is the most common ED in primary care.

\section{INTRODUCTION}

Eating disorders (EDs) are severe chronic mental health disorders associated with negative outcomes and with the highest mortality among psychiatric disorders. ${ }^{12}$ Understanding changes in their incidence over time and variations by gender and age, is important in aiding

\section{ARTICLE SUMMARY}

Article focus

- Determining incidence rates of eating disorders (EDs) in primary care in the UK between 2000 and 2009 by age group and gender.

- Investigating changes in incidence of EDs between 2009 and 2000.

- Identify age peaks at incidence by gender.

Key messages

- The incidence of EDs varied by gender and ED type. ED not otherwise specified was the most common incident ED in males and females.

- There was a significant increase during the 10 years under study in the overall incidence of diagnosed EDs both in males and females.

- Peak age at diagnosis varied across genders and by ED type. Adolescent girls aged 15-19 had the highest incidence of EDs (2 per 1000).

Strengths and limitations of this study

- This study is representative of the general population.

- Incidence rates obtained from primary care allow inclusion of all cases presenting to healthcare settings, not just cases presenting to secondary/ tertiary care (referral bias).

- However, incidence rates obtained in this study are likely to be an underestimate of incident cases present in the community.

causal investigations and service provision. Differences across studies in the incidence of EDs have been reported mainly due to the different populations and nature of the samples studied: primary care registers ${ }^{3}{ }^{4}$ or community samples. ${ }^{56}$ Owing to the relatively low incidence rates of $\mathrm{ED}$ in the community, studying the incidence of ED at community level is extremely difficult and costly, hence electronic databases and primary care registers can play an important role in understanding the changes in the number of individuals developing a disorder and seeking help.

Most studies so far have highlighted consistent incidence rates in primary care (ie, a 
stable number of individuals with a new ED diagnosis) for anorexia nervosa (AN) in the 1980s and 1990s; however, a recent Dutch study highlighted an increase in the incidence of AN in girls aged 15-19 in the 1990s compared to the 1980s. ${ }^{4}$ With regards to bulimia nervosa (BN), after an increase in new diagnoses in the 1980s and mid-1990s, ${ }^{3} 78$ recent findings have suggested a possible decrease or stabilisation since the late 1990s. ${ }^{3}{ }^{4}$

Unspecified eating disorders, commonly grouped under the 'not Otherwise Specified' diagnostic category (EDNOS) have been far less studied than AN and BN. Although EDNOS is the disorder most commonly seen in secondary/tertiary care settings ${ }^{9}{ }^{10}$ and in general population samples ${ }^{11}$ the incidence of EDNOS has not been previously estimated in primary care.

We aimed to (1) estimate the incidence rates of ED, as well as incidence rates of AN, BN and EDNOS separately, in primary care in the UK between 2000 and 2009 by age group and gender; (2) investigate whether the incidence of diagnosed ED changed in 2009 compared to 2000; and (3) identify peaks in the incidence of diagnosed ED by gender and age group.

\section{METHOD}

Sample

We used data from the General Practice Research Database (GPRD), a large automated anonymised UK medical record database containing information from some 400 general practices with a cumulative follow-up time of more than 40 million person-years (representing approximately $5 \%$ of the general UK population). The general practitioners (GPs) who contribute data to the GPRD use office computers in their routine practice to record medical information including demographic data, medical diagnoses and deaths in a standard, anonymous format and agree to provide data for research purposes to the GPRD. The practices included are broadly representative of UK general practices in terms of geographic distribution, gender and age of registered patients and practice size. ${ }^{12}$

The period for this study was 1 January 2000 to 31 December 2009.

We identified all subjects aged 10-49 years for whom data were recorded in the GPRD during the study period. To be eligible for inclusion, patients had to have been registered with the GP for at least 6 months before the first recorded diagnosis and to be 10-49 years of age at the time of diagnosis. This age-range was chosen given the very rare number of new onset cases before age 10 and after age $49 .^{38}$

\section{Validity of diagnoses}

The comprehensive nature of the information on clinical diagnoses recorded in the GPRD has been repeatedly validated and found to be of high quality for the purpose of conducting epidemiological research ${ }^{13} 14$ (for a systematic review see ${ }^{15} 16$ ). In particular, ED diagnoses were found to have a positive predictive value of $>90 \%,{ }^{816}$ therefore reliable for identifying ED cases.

\section{Case definition}

Patients were identified as incident cases of ED if they had a first time diagnosis of $\mathrm{AN}, \mathrm{BN}$ or EDNOS recorded in their computerised medical record between 1 January 2000 and 31 December 2009 with no prior recorded ED diagnosis. We used diagnostic codes from a modified version of the Read classification system (Read codes are a standard hierarchical classification system for recording medical information in UK primary care settings) (specific codes available on request). ${ }^{17} 18$

Cases were classified according to the type of ED (AN, $\mathrm{BN}$ or EDNOS) that was recorded.

All cases receiving a diagnosis of EDNOS were identified using the 'ED unspecified' code and the 'Atypical AN' and 'Atypical BN' (codes based on the International Classification of Diseases and Related Health Problems, Tenth revision-ICD-10, ${ }^{19}$ which uses the 'Eating Disorder unspecified' notation for EDNOS). EDNOS cases did not have a prior or subsequent diagnosis of either AN or BN within the study period.

Information on weight and height and body mass index (BMI) at the time of diagnosis was also evaluated by one of the authors (NM) for 10\% of all records (where this information was available in the computerised record) for quality control purposes.

Records of patients who received more than one diagnosis of $\mathrm{AN}$ and $\mathrm{BN}$ within 3 months were all reviewed by hand and BMI and ED symptoms recorded at the time of diagnosis were used to classify the patient's ED type using an algorithm. When a patient had a diagnosis of both AN and BN within 3 months and the subject had a BMI and symptoms consistent with one diagnosis (AN or BN), they were considered an incident case of either AN or BN. If the two diagnoses were recorded at least 1 month apart, and neither BMI nor symptoms were recorded at the time of diagnosis or if BMI or symptoms were consistent with having both $\mathrm{AN}$ and $\mathrm{BN}$, then the patient was classified as having an incident case of both $\mathrm{AN}$ and $\mathrm{BN}$. If the patient received $\mathrm{AN}$ and $\mathrm{BN}$ diagnoses on the same day and no BMI or symptoms were recorded, we assumed that the patient had an ED, but could not assign them to $\mathrm{AN}$ or $\mathrm{BN}$; therefore, they were classified as having EDNOS.

The index date was the date of the first diagnosis of $\mathrm{AN}, \mathrm{BN}$ or EDNOS recorded by the GP.

\section{Incidence rates}

Total, age-specific, gender-specific and year-specific annual incidence rates (IRs) of ED diagnoses (all types) and $95 \%$ CIs were calculated. The number of incident cases was divided by the number of subjects aged 10-49 registered in GPRD during the calendar year under study (the population at risk). We stratified the annual IRs by age group $(10-14,15-19,20-29,30-39$ and 40 
49 years), gender and type of ED recorded (AN, BN or EDNOS).

Age-standardised annual IRs for EDs were calculated using the direct method, using annual mid-year UK population estimates for the UK data for 2000 and 2009 obtained from the Office of National Statistics (ONS) ${ }^{20}$ and $95 \%$ CIs were calculated based on the Poisson approximation. Standardised rates were calculated for all and by gender and used to compare changes in the recorded incidence between 2000 and 2009 using the iri command in Stata V.12 (Stata Corp).

We calculated the stratified age and gender-specific IR by ED diagnosis for the year 2009.

\section{Ethics}

The protocol for this study was reviewed and approved by the Independent Scientific Advisory Committee (ISAC) of the Medicines and Healthcare Products Regulation Agency (MHRA).

\section{RESULTS}

We identified 9120 patients with a first-time diagnosis of ED (AN, BN or EDNOS) recorded in the GPRD during the study period (2000-2009).

Cases with co-occurring diagnoses were reviewed by hand. Among the 69 patients who received a first-time diagnosis of $\mathrm{AN}$ and $\mathrm{BN}$ within a 3-month period, 18 cases were classified as incident cases of AN and 21 were classified as incident cases of BN. In 21 cases, both AN and $\mathrm{BN}$ diagnoses were plausible and these were considered to have both an incident AN and BN diagnosis. Nine cases received two diagnoses on the same day and these cases were considered to have incident EDNOS.

A total of 2134 cases $(23.5 \%)$ were classified as incident cases of AN during the study period; 3433 cases $(37.8 \%)$ were considered incident cases of $\mathrm{BN}$; and 3505 $(38.6 \%)$ were classified as incident cases of EDNOS.

\section{Annual incidence rates}

Annual Crude IRs of all ED across genders and stratified by gender are shown in the online supplementary table S1. The overall crude IR of diagnosed ED was 33.0 (95\% CI 30.7 to 35.3 ) in 2000 and 36.8 (95\% CI 34.4 to 39.2) per 100000 in 2009 (see table 1).

Age-standardised rates of ED were 32.3 (95\% CI 31.7 to 32.9) per 100000 in 2000 and 37.2 (95\% CI 36.6 to
37.9) per 100000 in 2009, showing a statistically significant increase $(\mathrm{p}<0.000001$; see table 1$)$.

\section{Gender-specific incidence rates \\ Females}

There was evidence that the overall incidence of ED steadily increased in the period under study for females aged 10-49 (see online supplementary table S1). The incidence of diagnosed ED in the last 3 years of the study period (2007-2009) was higher compared to 2000-2002 with a peak of 63.8 (59.7 to 68.2) per 100000 in 2008 (see online supplementary table S1).

The age-standardised rates of ED in females significantly increased between 2000 and 2009 from 51.8 (95\% CI 50.6 to 52.9) per 100000 to 62.6 (95\% CI 61.4 to $63.8)$ in $2009(\mathrm{p}<0.00001$; see table 1$)$.

The incidence of AN in females was stable during the study period despite some minor fluctuations across the years (figure 1). A formal comparison between the annual IR of diagnosed AN in 2000 and 2009 showed no differences in rates.

The incidence of $\mathrm{BN}$ also remained stable during the first decade of the 2000s (see figure 1).

There was evidence of a steady increase in the incidence of diagnosed EDNOS in females aged 10-49 during the study period. In 2000, the IR was 17.7 (95\% CI 15.5 to 20.0 ) per 100000 compared to 28.4 (95\% CI 25.6 to 31.4) per 100000 in 2009 (see online supplementary table S1 and figure 1). There was a significant increase in 2009 compared to $2000(p<0.00001)$. During the time under study, EDNOS became the most common incident ED diagnosis in females aged 10-49 (figure 1).

\section{Males}

The annual crude and age-standardised incidence estimates were similar and increased during the study period (see table 1). The annual age-standardised incidence of diagnosed ED in males significantly increased from 5.6 (95\% CI 5.3 to 6.0) per 100000 in 2000 to 7.1 (95\% CI 6.7 to 7.5$)$ per 100000 in 2009 $(\mathrm{p}<0.00001)$.

The incidence of diagnosed AN in males remained stable during the study period (see figure 2). The difference in IR between 2000 and 2009 was not statistically significant.

\begin{tabular}{|c|c|c|c|c|c|c|}
\hline & \multicolumn{3}{|l|}{2000} & \multicolumn{3}{|c|}{2009} \\
\hline & $\mathbf{N}$ & $\begin{array}{l}\text { Crude incidence } \\
(95 \% \mathrm{Cl})\end{array}$ & $\begin{array}{l}\text { Age-standardised } \\
\text { incidence }(95 \% \mathrm{Cl})\end{array}$ & $\mathbf{N}$ & $\begin{array}{l}\text { Crude incidence } \\
(95 \% \mathrm{Cl})\end{array}$ & $\begin{array}{l}\text { Age-standardised } \\
\text { incidence }(95 \% \mathrm{Cl})\end{array}$ \\
\hline Overall & 789 & 33.0 (30.7 to 35.3$)$ & 32.3 (31.7 to 32.9$)$ & 897 & 36.8 (34.4 to 39.2$)$ & 37.2 (36.6 to 37.9$)$ \\
\hline Females & 732 & 53.2 (49.5 to 57.2$)$ & 51.8 (50.6 to 52.9$)$ & 816 & 62.7 (58.4 to 67.1$)$ & 62.6 (61.4 to 63.8$)$ \\
\hline Males & 57 & 5.6 (4.3 to 7.2$)$ & $5.6(5.3$ to 6.0$)$ & 81 & 7.1 (5.7 to 8.8$)$ & $7.1(6.7$ to 7.5$)$ \\
\hline
\end{tabular}


Figure 1 Incidence rates and 95\% Cls of anorexia nervosa (AN), bulimia nervosa (BN), and eating disorder not otherwise specified (EDNOS) by year for females aged $10-49$ years.

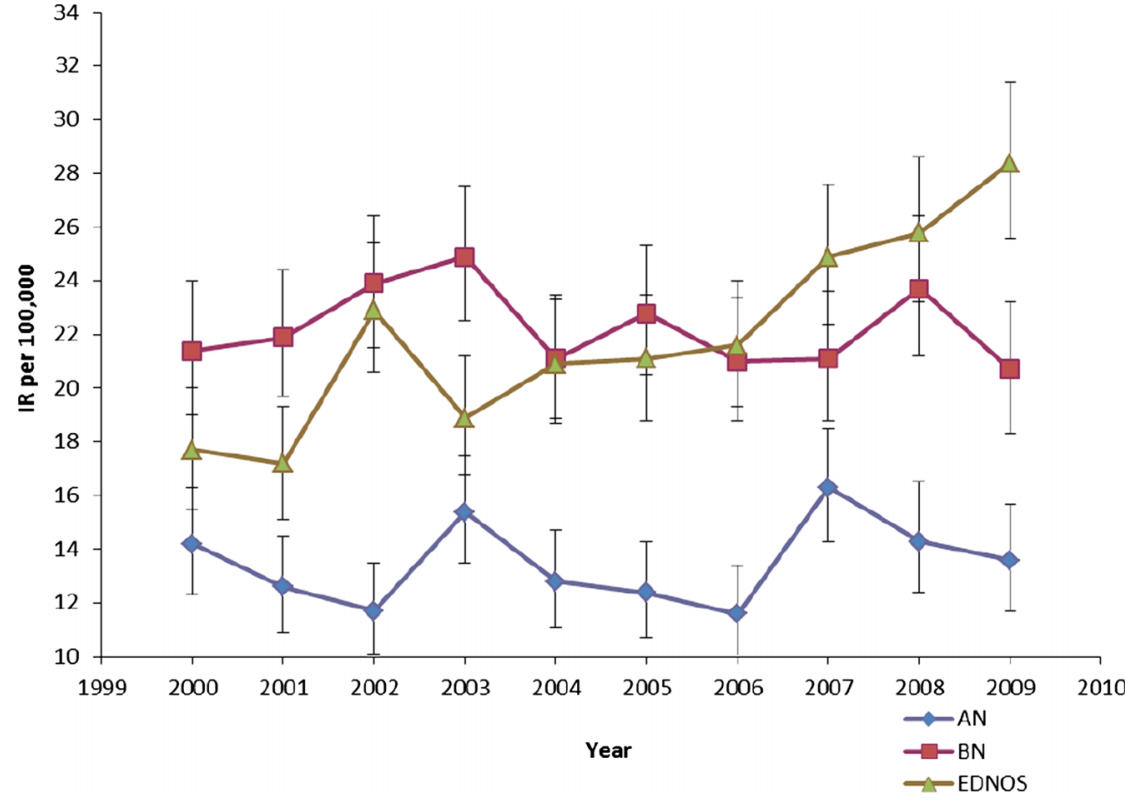

The highest incidence of $\mathrm{AN}, \mathrm{BN}$ and EDNOS was for girls between 15 and 19 years of age (see table 3). In this age range, the IR for all diagnosed ED was 164.5 (95\% CI 144.6 to 186.4) per $100000(0.2 \%)$ (table 2). Although the peak age at incident diagnosis for both $\mathrm{AN}$ and $\mathrm{BN}$ was 15-19 years, 24.0 (95\% CI 16.3 to 34.3) per 100000 girls had an onset of $\mathrm{AN}$ between the ages of 10-14 years. In contrast, diagnoses of BN peaked between 15 and 19 years and IR continued to be elevated for those aged 20-29 years (see table 3).

EDNOS was the most common incident diagnosed ED among females aged 10-49: 28.4 (95\% CI 25.6 to 31.4) per 100000 in 2009.
Figure 2 Incidence rates and $95 \% \mathrm{Cls}$ of anorexia nervosa (AN), bulimia nervosa (BN), and eating disorder not otherwise specified (EDNOS) by year for males aged $10-49$ years.

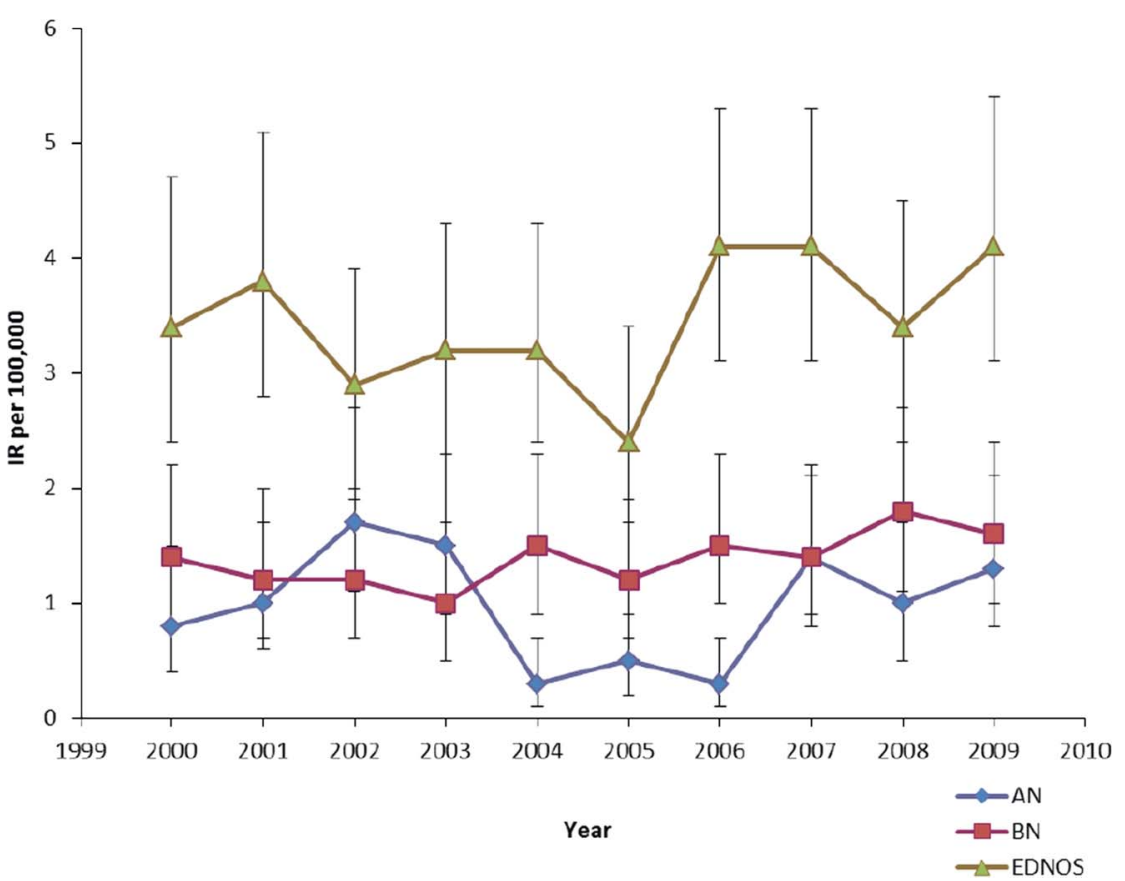




\section{Males}

In 2009, the crude IR for diagnosed ED for males aged 10-49 years was 7.1 (95\% CI 5.7 to 8.8) per 100000 (see online supplementary table S1). The peak age of incidence of diagnosed AN in males was 15-19 years (IR 3.8/100 000, 95\% CI 1.4 to 8.3). Diagnosed BN peaked between the ages 20 and 29: 4.7 (95\% CI 2.6 to 7.8) per 100000 . In contrast to females, EDNOS diagnoses in boys peaked between the ages 10- 14 years (IR 15.0/ $100000,95 \%$ CI 9.1 to 23.2). EDNOS was the most commonly diagnosed ED in males aged 10-49 (IR 4.2/ $100000,95 \%$ CI 3.1 to 5.5 ) (see online supplementary table S1).

In 2009, the female to male ratio was 11.8:1 for $\mathrm{AN}$, 14.9:1 for BN and 7.7:1 for EDNOS.

\section{DISCUSSION}

This is the most comprehensive study of the incidence of EDs in primary care to date including $~ 40$ million person-years of follow-up. We showed that the annual age-standardised incidence of ED in the UK significantly increased between 2000 and 2009. This increase was due to a higher number of new EDNOS diagnoses in the last third of the decade, while the number of new diagnoses of $\mathrm{AN}$ and $\mathrm{BN}$ remained stable across the study period. The peak age of onset for an ED diagnosis in females was between 15 and 19 years. In this age range, the incidence of ED for females was $0.2 \%$ of the population in 2009. A slightly different pattern of incident diagnosis was observed for males with the peak age of onset at 15-19 years for AN, 10-14 years for EDNOS and 20-29 years of age for BN. While IR became higher than those of $\mathrm{AN}$ and $\mathrm{BN}$ over the decade, interestingly, IR of EDNOS in males were higher compared to those of AN and $\mathrm{BN}$ throughout the decade, suggesting that males more often receive a diagnosis of EDNOS compared to $\mathrm{AN}$ and $\mathrm{BN}$ in primary care in the UK.

Although the lifetime prevalence of $\mathrm{BN}$ has been shown to be roughly double of that of $\mathrm{AN}(0.5 \%$ vs $0.3 \%$ ) in males in the general population, ${ }^{21}$ we found an IR ratio closer to 1 for diagnosed $\mathrm{BN}$ and $\mathrm{AN}$ in this study. This might suggest that males are not being diagnosed with $\mathrm{BN}$ in general practice in the UK.

This is the first study to investigate the incidence of all $\mathrm{ED}$, including EDNOS, in primary care. Incidence rates of diagnosed AN in the current study were consistent with the previous studies on the incidence of $\mathrm{AN}$ in the UK using the GPRD. ${ }^{3} 8$ A study using a primary care sample in the Netherlands highlighted an increased incidence rate of AN among adolescent girls in the $1990 \mathrm{~s},{ }^{4}$ while 15-19 was the peak age at diagnosis of AN in our study, we found an incidence rate for girls in this age group of 49.6/100 000 in 2009, lower than the 109.2/ 100000 person-years reported in the Dutch Study during the 1990 s. $^{4}$

Despite some indications of a decreasing incidence of $\mathrm{BN}$ in the late $1990 \mathrm{~s},{ }^{3}{ }^{4}$ in the $2000 \mathrm{~s}$, our study suggests a stabilisation of incidence since the late 1990s. As suggested by Currin et $a l^{3}{ }^{3}$ the peaks of newly diagnosed cases in the mid-1990s and late 1990s probably corresponded to an increased recognition and detection of a relatively 'new' disorder, which has now stabilised at its true level.

To our knowledge, this is the first study to estimate the incidence of EDNOS in primary care. Although this disorder was previously considered as encompassing a group of patients with less severe disorders than the classical $\mathrm{AN}$ and $\mathrm{BN}$, recent focus on the impact and epidemiology of EDNOS 102223 has highlighted its clinical and public health impact. EDNOS is acknowledged not only as the most prevalent ED in clinical and epidemiological samples ${ }^{9} 1024$ but also as severe as $\mathrm{AN}$ and $\mathrm{BN}$ in terms of clinical impact and outcomes.

Our findings of an increase in ED diagnoses over the first decade of the 2000s is consistent with two notmutually exclusive possible explanations: the increase might be secondary to improved recognition and diagnosis at a primary care level or a true increase in the number of participants developing ED.

This possibly explains the highlighted increase in EDNOS diagnoses in the latter part of the 2000s, maybe secondary to the increased research carried out on EDNOS resulting in the increased awareness to the wider spectrum of ED that do not fit into the diagnoses of $\mathrm{AN}$ and $\mathrm{BN}$. However, increased diagnoses might also result from increased presentations to primary care due to a true increase in disorders.

\section{Strengths and limitations}

GPRD is one of the largest sources of primary care data in the world. Using such a large and independently

Table 2 Incidence of ED per 100000 population for the year 2009 by age and gender

\begin{tabular}{|c|c|c|c|c|c|c|}
\hline \multicolumn{7}{|c|}{ All eating disorders } \\
\hline \multirow[b]{2}{*}{ Age (years) } & \multicolumn{3}{|l|}{ Females } & \multicolumn{3}{|l|}{ Males } \\
\hline & Cases (N) & Population (N) & Incidence $(95 \% \mathrm{Cl})$ & Cases (N) & Population (N) & Incidence $(95 \% \mathrm{Cl})$ \\
\hline $10-14$ & 74 & 116476 & 63.5 (50.2 to 79.3$)$ & 21 & 120219 & 17.5 (11.1 to 26.2$)$ \\
\hline $15-19$ & 239 & 145279 & 164.5 (144.6 to 186.4$)$ & 23 & 132375 & $17.4(11.3$ to 25.6$)$ \\
\hline $20-29$ & 309 & 349163 & 88.5 (79.4 to 98.8$)$ & 28 & 277454 & $10.1(6.8$ to 14.4$)$ \\
\hline 30-39 & 138 & 338255 & 40.8 (34.4 to 48.0$)$ & 6 & 288468 & 2.1 (0.8 to 4.3$)$ \\
\hline $40-49$ & 56 & 352843 & 15.9 (12.1 to 20.5$)$ & 3 & 319724 & 0.9 (0.2 to 2.5$)$ \\
\hline
\end{tabular}


Table 3 Incidence of eating disorders per 100,000 population for the year 2009 by age, sex and type of eating disorder

\begin{tabular}{|c|c|c|c|c|c|c|c|c|c|}
\hline \multirow[b]{2}{*}{ Age (years) } & \multicolumn{3}{|l|}{ Females } & \multicolumn{3}{|l|}{ Males } & \multicolumn{3}{|l|}{ Total } \\
\hline & Cases (N) & Population (N) & Incidence $(95 \% \mathrm{Cl})$ & Cases (N) & Population (N) & Incidence $(95 \% \mathrm{Cl})$ & Cases (N) & Population (N) & Incidence $(95 \% \mathrm{Cl})$ \\
\hline \multicolumn{10}{|c|}{ Anorexia nervosa } \\
\hline $10-14$ & 28 & 116476 & 24.0 (16.3 to 34.3$)$ & 3 & 120219 & 2.5 (0.6 to 6.8$)$ & 31 & 236695 & $13,1(9.0$ to 18.4$)$ \\
\hline $15-19$ & 69 & 145279 & 47.5 (37.2 to 59.8$)$ & 5 & 132375 & 3.8 (1.4 to 8.3$)$ & 74 & 277654 & 26.7 (21.1 to 33.3$)$ \\
\hline $20-29$ & 66 & 349163 & 18.9 (14.8 to 23.9 ) & 5 & 277454 & $1.8(0.7$ to 4.0$)$ & 71 & 626617 & 11.3 (8.9 to 14.2$)$ \\
\hline $30-39$ & 10 & 338255 & 3.0 (1.5 to 5.3$)$ & 1 & 288468 & $0.3(0.2$ to 1.7$)$ & 11 & 626723 & 1.8 (0.9 to 3.0$)$ \\
\hline $40-49$ & 4 & 352843 & 1.1 (0.4 to 2.7$)$ & 1 & 319724 & $0.3(0.1$ to 1.5$)$ & 5 & 672567 & 0.7 (0.3 to 1.6$)$ \\
\hline $10-49$ & 177 & 1302016 & $13.6(11.7$ to 15.7$)$ & 15 & 1138240 & $1.3(0.8$ to 2.1$)$ & 192 & 2440256 & $7.9(6.8$ to 9.0$)$ \\
\hline \multicolumn{10}{|c|}{ Bulimia nervosa } \\
\hline $10-14$ & 7 & 116476 & 6.0 (2.6 to 11.9$)$ & 0 & 120219 & 0 & 7 & 236695 & 2.9 (1.1 to 5.6$)$ \\
\hline $15-19$ & 68 & 145279 & 46.8 (36.6 to 58.9$)$ & 4 & 132375 & 3.0 (0.9 to 7.3$)$ & 72 & 277654 & 25.9 (20.1 to 32.4$)$ \\
\hline $20-29$ & 111 & 349163 & $31.8(26.3$ to 38.1$)$ & 13 & 277454 & 4.7 (2.6 to 7.8$)$ & 124 & 626617 & 19.8 (16.4 to 23.2$)$ \\
\hline $30-39$ & 65 & 338255 & 19.2 (15.0 to 24.3 ) & 1 & 288468 & 0.3 (0.2 to 1.7$)$ & 66 & 626723 & 10.5 (8.2 to 13.3$)$ \\
\hline $40-49$ & 18 & 352843 & 5.1 (3.1 to 7.9 ) & 0 & 319724 & 0 & 18 & 672567 & 2.7 (1.6 to 3.8$)$ \\
\hline $10-49$ & 269 & 1302016 & 20.7 (18.3 to 23.2$)$ & 18 & 1138240 & $1.6(1.0$ to 2.4$)$ & 287 & 2440256 & 11.8 (10.5 to 13.2$)$ \\
\hline \multicolumn{10}{|c|}{ Eating disorder NOS (EDNOS) } \\
\hline $10-14$ & 39 & 116476 & 33.5 (24.1 to 45.3$)$ & 18 & 120219 & 15.0 (9.1 to 23.2$)$ & 57 & 236695 & 24.1 (18.4 to 31.0$)$ \\
\hline $15-19$ & 102 & 145279 & 70.2 (57.5 to 84.9$)$ & 14 & 132375 & $10.6(6.0$ to 17.3$)$ & 116 & 277654 & 41.8 (34.7 to 49.9$)$ \\
\hline $20-29$ & 132 & 349163 & 37.8 (31.8 to 44.7$)$ & 9 & 277454 & $3.2(1.6$ to 5.9$)$ & 142 & 626617 & 22.7 (19.2 to 26.6$)$ \\
\hline $30-39$ & 63 & 338255 & $18.6(14.4$ to 23.7$)$ & 4 & 288468 & $1.4(0.4$ to 3.3$)$ & 67 & 626723 & $10.7(8.3$ to 13.5$)$ \\
\hline $40-49$ & 34 & 352843 & $9.6(6.8$ to 13.3$)$ & 2 & 319724 & $0.6(0.1$ to 2.0$)$ & 36 & 672567 & 5.3 (3.8 to 7.3$)$ \\
\hline $10-49$ & 370 & 1302016 & 28.4 (25.6 to 31.4$)$ & 48 & 1138240 & 4.2 (3.1 to 5.5$)$ & 418 & 2440256 & 17.1 (15.5 to 18.8$)$ \\
\hline
\end{tabular}

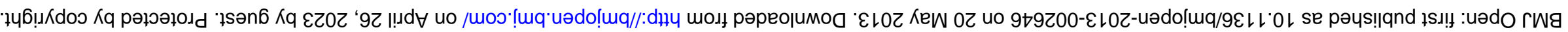


collected dataset, largely representative of GP practices in the UK, allowed us to estimate the incidence of presentations in a general practice setting. Access to primary care is universal in the UK; therefore, the results of this study are generalisable to the UK population. Moreover, estimating incidence rates in a primary care setting ensures the inclusion of mild cases, who normally would not be referred on to specialist services. Given the nature of GPRD, we were unable to systematically ensure that all diagnoses met with the DSM-IV or ICD-10 criteria for ED; however, general practitioners incorporate data from secondary or tertiary care in the GPRD electronic records when patients are referred; therefore, it is possible that some diagnoses included in the database were in fact made by psychiatrists. Moreover, GP diagnoses of EDs (and of mental health disorders) in GPRD have been shown to be highly valid. ${ }^{15} 16$ If patients were misclassified, it is likely that the diagnostic subgroup might change, but not the total incidence of ED diagnoses. This is likely to be particularly relevant to EDNOS, as this diagnosis has not been previously validated in GPRD.

Given that our incidence rates are derived from primary care diagnoses, they allow the ascertainment of 'detected' incidence rates rather than community incidence rates (see figure 3) and are a close reflection of healthcare need. There is evidence that true rates might be double or triple of those detected in a healthcare setting. ${ }^{56}$

\section{CONCLUSIONS}

In summary, the incidence of diagnosed ED in the UK significantly increased between 2009 and 2000.

The incidence of AN and BN has remained stable in males and females in the first decade of the 21 century; however, the incidence of EDNOS increased.

At the peak age of diagnosis (age 15-19 years), it is estimated that 2 girls/1000 are likely to be newly diagnosed with an ED in the UK. The incidence in this age group suggests that ED may be the most common new onset mental health disorder in adolescent girls after depression, 11.9 in 1000 girls aged 15-19 received a diagnosis of depression in GPRD in $2009 .{ }^{25}$ In girls aged $10-19$, the

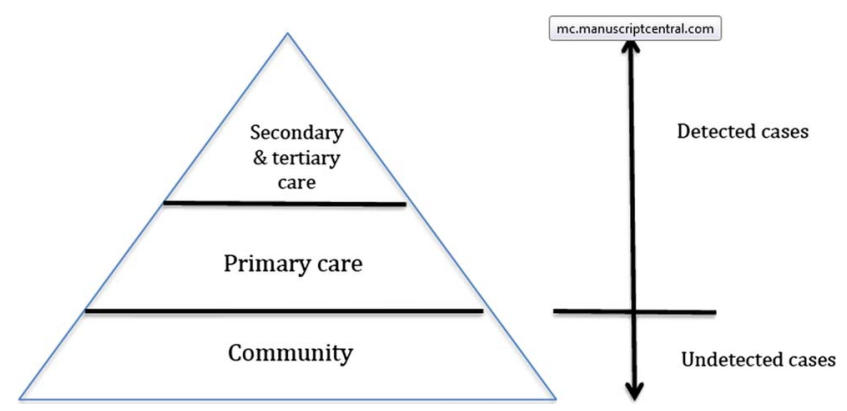

Figure 3 Incidence of disorders in the community and in the healthcare setting. incidence rate of ED is about ninefold higher than the incidence rate of diagnosed type 1 diabetes in the UK (1.2 per 1000 for ED vs 0.26 per 1000 for type 1 diabetes), and about half that of type 2 diabetes (3.6 per 1000). ${ }^{26}$

Future research should clarify whether the increase seen in this study reflects a true community increase or better detection. Our findings have important implications for public health, healthcare provision and understanding the development of EDs.

Contributors NM and JLT were involved in the conception and design of the study. NM, KWH, JLT and IP performed the analysis and interpretation of the data and drafted the article. JLT, KWH and IP were involved in critical the revision of the manuscript. All authors have read and approved the final manuscript.

Funding This research was funded by a National Institute of Health Research (NIHR) clinician scientist award (DHCS/08/08/012) to Dr N Micali. The views expressed in this publication are those of the author(s) and not necessarily those of the NHS, the National Institute for Health Research or the Department of Health.

Competing interests None.

Ethics approval Independent Scientific Advisory Committee (ISAC) of the Medicines and Healthcare Products Regulation Agency (MHRA).

Provenance and peer review Not commissioned; externally peer reviewed.

Data sharing statement No additional data are available.

\section{REFERENCES}

1. Arcelus $\mathrm{J}$, Mitchell $\mathrm{AJ}$, Wales $\mathrm{J}$, et al. Mortality rates in patients with anorexia nervosa and other eating disorders: a meta analysis of 36 studies. Arch Gen Psychiatry 2011;68:724-31.

2. Field AE, Sonnenville $\mathrm{K}$, Micali $\mathrm{N}$, et al. Common eating disorders predictive of adverse outcomes are missed by the DSM-IV and DSM-5 classifications. Pediatrics 2012;130:e289-95.

3. Currin L, Schmidt U, Treasure J, et al. Time trends in eating disorder incidence. Br J Psychiatry 2005;186:132-5.

4. Van Son GE, Van Hoeken D, Bartelds Al, et al. Time trends in the incidence of eating disorders: a primary care study in the Netherlands. Int J Eat Disord 2006;39:565-9.

5. Keski-Rahkonen A, Hoek HW, Susser ES, et al. Epidemiology and course of anorexia nervosa in the community. Am J Psychiatry 2007;164:1259-65.

6. Keski-Rahkonen A, Hoek HW, Linna MS, et al. Incidence and outcomes of bulimia nervosa: a nationwide population based study. Psychol Med 2009;39:823-31.

7. Hoek HW, Bartelds Al, Bosveld JJ, et al. Impact of urbanization on detection rates of eating disorders. Am $J$ Psychiatry 1995;152:1272-8.

8. Turnbull S, Ward A, Treasure J, et al. The demand for eating disorder care. An epidemiological study using the general practice research database. Br J Psychiatry 1996;169:705-12.

9. Fairburn CG, Cooper Z, Bohn K, et al. The severity and status of eating disorder NOS: implications for DSM-V. Behav Res Ther 2007:45:1705-15.

10. Nicholls DE, Lynn R, Viner R. Childhood eating disorders: British national surveillance study. Br J Psychiatry 2011;198:295-301.

11. Wade TD, Bergin JL, Tiggemann M, et al. Prevalence and long-term course of lifetime eating disorders in an adult Australian twin cohort. Aust N Z J Psychiatry 2006;40:121-8.

12. Office for National Statistics. Key Health Statistics from general practice 1996: Series MB6 No1. London: Office for National Statistics, 1998.

13. Jick SS, Kaye JA, Vasilakis-Scaramozza C, et al. Validity of the general practice research database. Pharmacotherapy 2003;23:686-9.

14. Jick $H$, Terris BZ, Derby LE, et al. Further validation of information recorded on a general practitioner based computerized data resource in the UK. Pharmacoepidemiol Drug Saf 1992;1:347-9.

15. Hammad TA, McAdams MA, Feight A, et al. Determining the predictive value of Read/OXMIS codes to identify incident acute myocardial infarction in the General Practice Research Database. Pharmacoepidemiol Drug Saf 2008;17:1197-201. 
16. Herrett E, Thomas SL, Schoonen WM, et al. Validation and validity of diagnoses in the General Practice Research Database: a systematic review. Br J Clin Pharmacol 2010;69:4-14.

17. Khan NF, Harrison SE, Rose PW. Validity of diagnostic coding within the General Practice Research Database: a systematic review. Br J Gen Pract 2010;60:e128-36.

18. Dave' S, Petersen I. Creating medical and drug code lists to identify cases in primary care databases. Pharmacoepidemiol Drug Saf 2009:18:704-7.

19. World Health Organisation. ICD-10 Classifications of mental and behavioural disorder: clinical descriptions and diagnostic guidelines. Geneva: World Health Organisation, 1992.

20. Office for National Statistics. Mid-year population estimates. United Kingdom. Office for National Statistics. Key population and vital statistics series VS NO 30, PP1 No. 26, 2003.

21. Hudson J, Hiripi E, Pope HG, et al. The prevalence and correlates of eating disorders in the National Comorbidity Survey Replication. Biol Psychiatry 2007;61:348-58.
22. Fairburn CG, Bohn K. Eating disorder NOS (EDNOS): an example of the troublesome "not otherwise specified" (NOS) category in DSM-IV. Beh Res Ther 2005;43:691-701.

23. Hay PJ, Mond J, Buttner P, et al. Eating disorder behaviors are increasing: findings from two sequential community surveys in South Australia. PLOS ONE 2008;3:e1541.

24. Swanson SA, Crow SJ, Le Grange D, et al. Prevalence and correlates of eating disorders in adolescents. Results from the national comorbidity survey replication and adolescent supplement. Arch Gen Psychiatry 2011;68:714-23.

25. Wijlaars LP, Nazareth I, Petersen I. Trends in depression and antidepressant prescribing in children and adolescents: a cohort study in The Health Improvement Network (THIN). PLOS ONE 2012; 7:e33181.

26. González EL, Johansson S, Wallander MA, et al. Trends in the prevalence and incidence of diabetes in the UK: 1996-2005. J Epidemiol Community Health 2009;63:332-6. 